\title{
Routine preoperative obstructive sleep apnea screening of elective surgical patients: a single-centre three-month experience
}

\author{
Donald J. Young, MD, FRCPC (10 - Alexander Dotto, MD • Andrew G. Pritchard, BMSc • \\ Jusung Hwang, MD • Heather Cadenhead, MD • Lauren DeGroot, MD • \\ Michael van der Westhuizen, MD • Simon L. Adamson, MD • Lisa Jin, MD • \\ Dannielle Tinker, MD
}

Received: 2 July 2018/Revised: 6 January 2019/Accepted: 14 January 2019/Published online: 14 February 2019

(C) Canadian Anesthesiologists' Society 2019

\section{To the Editor,}

Routine preoperative screening for obstructive sleep apnea (OSA) has been recommended by the Society of Anesthesia \& Sleep Medicine ${ }^{1}$ and the American Society of Anesthesiologists. ${ }^{2}$ These recommendations come with the backing of evidence suggesting that OSA screening helps to reduce postoperative OSA-related complications. Both groups also acknowledge clinical, clerical, and economic burdens imposed by routine screening.

Poised with the burden of implementing routine OSA screening, we set about collecting our hospitals' OSA screening and complication demographics for three months. We sought to understand how routine screening may impact our local practice.

With Research Ethics Board approval and patient consent, we conducted routine preoperative OSA screening of our tertiary care adult non-obstetrical elective surgery patients at Vancouver General Hospital

D. J. Young, MD, FRCPC $(\varangle) \cdot$ H. Cadenhead, MD .

M. van der Westhuizen, MD - S. L. Adamson, MD .

D. Tinker, MD

Department of Anesthesia and Perioperative Care, Vancouver General Hospital, University of British Columbia, Vancouver, BC, Canada

e-mail: Donald.Young@vch.ca

\section{A. Dotto, MD}

Department of Anesthesia \& Perioperative Care, School of Population and Public Health, UBC Faculty of Medicine,

Vancouver, BC, Canada

\section{A. G. Pritchard, BMSc}

Schulich School of Medicine \& Dentistry, Western University, London, ON, Canada

J. Hwang, MD - L. DeGroot, MD - L. Jin, MD

UBC Faculty of Medicine, Vancouver, BC, Canada
\& UBC Hospital (affiliated sites) from June 5 to August 25, 2017. Screening was conducted either in the Anesthesia Consult Clinic or just prior to surgery. Six routinely collected recovery room complications recorded by postanesthesia care unit (PACU) nurses were tabulated the day following surgery.

Of 1,892 patients approached, 1,761 consented to enrolment. This represented $12.9 \%$ of the total elective surgical patients at our two hospitals for 2017. The proportional distributions of patients at the two hospital sites and across all surgical specialties were greater than $10 \%$ of the total patients for 2017 with one exception (otolaryngology 9.6\%).

By recall, 298 patients $(17 \%)$ reported previous overnight sleep studies. Of these, $66 \%$ reported positive studies for OSA, representing $11 \%$ of the total study cohort. Those with negative or no prior sleep evaluation (1,563 patients, $89 \%$ of the study cohort) were screened for OSA using STOP-BANG scoring.

The greatest utility of STOP-BANG is its ability to rule out severe OSA with scores $<3$. Nevertheless, the low specificity at this cut-off results in many false positive scores $\geq 3$. $^{3}$ Literature advocates a less sensitive but more specific cut-off of $\geq 5$ for a positive screen, but stipulates using this cut-off in surgical populations with low prevalence of OSA without specifying how low this prevalence should be. ${ }^{4}$

Using a STOP-BANG cut-off of $\geq 3,840$ (54\%) of the screened patients were positive. This compares with 239 (15\%) of positive screened patients at a cut-off of $\geq 5$. It is not tenable to work with over half of your elective patient population being labelled as screen-positive for OSA with scores $\geq 3$. Of the cohort sampled then, $11 \%$ had a previous diagnosis of OSA, and $15 \%$ had STOP-BANG scores $\geq 5$, resulting in $26 \%$ of elective surgical patients 
Table Comparison of registered nurse-recorded complications encountered in the PACU* based on STOP-BANG $<3$ or $\geq 3$, and STOP-BANG $<5$ or $\geq 5$.

\begin{tabular}{|c|c|c|c|c|c|c|c|c|c|c|}
\hline \multirow[t]{2}{*}{ PACU complication } & \multicolumn{2}{|c|}{ STOP-BANG $<3$} & \multicolumn{2}{|c|}{ STOP-BANG $\geq 3$} & \multirow[b]{2}{*}{$\begin{array}{l}P \\
\text { value }\end{array}$} & \multicolumn{2}{|c|}{ STOP-BANG $<5$} & \multicolumn{2}{|c|}{ STOP-BANG $\geq 5$} & \multirow[b]{2}{*}{$\begin{array}{l}P \\
\text { value }\end{array}$} \\
\hline & $\begin{array}{l}n \text { for } \\
\text { analysis }\end{array}$ & $n(\%)$ & $\begin{array}{l}n \text { for } \\
\text { analysis }\end{array}$ & $n(\%)$ & & $\begin{array}{l}n \text { for } \\
\text { analysis }\end{array}$ & $n(\%)$ & $\begin{array}{l}n \text { for } \\
\text { analysis }\end{array}$ & $n(\%)$ & \\
\hline Desaturation $(\mathrm{VGH} \& \mathrm{UBCH}) \dagger$ & 633 & 28 & 680 & $\begin{array}{l}37 \\
(5.4)\end{array}$ & 0.32 & 1125 & $51(4.5)$ & 188 & ${ }^{12}(6.4)$ & 0.36 \\
\hline $\begin{array}{l}\text { Monitored bed required§ } \\
(\mathrm{VGH} \& \mathrm{UBCH}) \dagger\end{array}$ & 633 & $1(0.2)$ & 680 & $9(1.3)$ & 0.02 & 1125 & $6(0.53)$ & 188 & $4(2.1)$ & 0.04 \\
\hline $\begin{array}{l}\text { New PAP required } \\
(\mathrm{VGH} \& \mathrm{UBCH}) \dagger\end{array}$ & 633 & 0 & 680 & $5(0.7)$ & 0.06 & 1125 & 0 & 188 & $5(2.7)$ & $<0.001$ \\
\hline Post-op ventilation (VGH only) $\ddagger$ & 245 & $2(0.8)$ & 347 & $5(1.4)$ & 0.71 & 495 & $5(1.0)$ & 97 & $2(2.1)$ & 0.32 \\
\hline $\begin{array}{l}\text { Reintubation in PACU } \\
\text { (VGH only) } \ddagger\end{array}$ & 245 & 0 & 347 & 0 & - & 495 & 0 & 97 & 0 & - \\
\hline $\begin{array}{l}\text { Respiratory arrest in PACU (VGH } \\
\text { only) } \ddagger\end{array}$ & 245 & 0 & 347 & 0 & - & 495 & 0 & 97 & 0 & - \\
\hline
\end{tabular}

$\overline{\mathrm{ICU}}=$ intensive care unit; $\mathrm{OR}=$ operating room; OSA = obstructive sleep apnea; PACU = postanesthesia care unit; PAP = positive airway pressure treatment; $\mathrm{UBCH}=$ University of British Columbia Hospital; VGH = Vancouver General Hospital. *Not all study patients came to the PACU postoperatively. Potential reasons for this include bypassing the PACU on account of a procedure only under sedation, direct admission to the ICU, or cardiac surgery ICU from the OR, having a procedure out of the main OR such as in radiology or the cardiac catheterization laboratory, or the patient may not have come to surgery despite prior anesthesia consultation. $†$ Complication data collected at both VGH and UBCH sites routinely by the PACU nurses. $\$$ Complication data collected only at VGH site (a site of higher acuity care) routinely by PACU RNs. $\S$ Monitored bed refers to a minimum of continuous pulse oximetry monitoring and immediate nursing intervention if readings are low. Includes high acuity, step down, and critical care units. Data here represent monitoring ordered as a result of patient's stay in the PACU. This does not represent monitored beds ordered in advance of surgery.

being earmarked as potentially at risk of OSA-related complications.

The Table shows occurrences of the six registered nurserecorded PACU complications. Desaturation events did not correlate with higher STOP-BANG scores. Neither were patients with higher STOP-BANG scores more likely to be brought ventilated to the PACU. Arrangements for $24 \mathrm{hr}$ monitored care upon PACU discharge that was not arranged prior to surgery (ten out of 1,313 cases), and the need for initiation of new positive airway pressure therapy (five out of 1,313 cases) were correlated to higher STOP-BANG scores. No critical reintubations or respiratory failures occurred.

In summary, in this three-month trial of routine OSA screening, a quarter of our patients were earmarked with a potential for OSA-related issues postoperatively. Of the PACU complications reviewed, very few OSAattributable complications were encountered, none of which were critical. We acknowledge, of course, that OSA-related complications also occur outside the PACU. Such events were not followed up in this study cohort. The single-centre results presented here reflect the contemporary nature of perioperative OSA screening-a very high prevalence of screen positive patients at risk of infrequent but potentially harmful/lethal perioperative complications. ${ }^{5}$
Acknowledgements We extend our gratitude to Dr. Su-Yin Macdonell and Dr. Karolyn Arato for their review and comments of the material presented in this Letter to the Editor.

Editorial responsibility This submission was handled by Dr. Gregory L. Bryson, Deputy Editor-in-Chief, Canadian Journal of Anesthesia.

Commercial or non-commercial affiliations None.

Consultancies Mr. Julian Ho, University of BC Dept of Statistics, Vancouver, BC, Canada.

Funding sources None.

\section{References}

1. Chung F, Memtsoudis SG, Ramachandran SK, et al. Society of Anesthesia and Sleep Medicine guidelines on preoperative screening and assessment of adult patients with obstructive sleep apnea. Anesth Analg 2016; 123: 452-73.

2. American Society of Anesthesiologists Task Force on Perioperative Management of Patients with Obstructive Sleep Apnea. Practice guidelines for the perioperative management of patients with obstructive sleep apnea: an updated report by the American Society of Anesthesiologists Task Force on Perioperative Management of Patients with Obstructive Sleep Apnea. Anesthesiology 2014; 120: 268-86. 
3. Chung F, Abdullah HR, Liao P. STOP-Bang questionnaire. A practical approach to screen for obstructive sleep apnea. Chest 2016; 149: 631-8.

4. Ayas NT, Laratta CR, Coleman JM, et al. Knowledge gaps in the perioperative management of adults with obstructive sleep apnea and obesity hypoventilation syndrome. An official American Thoracic Society Workshop Report. Ann Am Thorac Soc 2018; 15: 117-26.
5. Ramachandran SK, Pandit J, Devine S, et al. Postoperative respiratory complications in patients at risk for obstructive sleep apnea: a single-institution cohort study. Anesth Analg 2017; 125: $272-9$.

Publisher's Note Springer Nature remains neutral with regard to jurisdictional claims in published maps and institutional affiliations. 